\title{
Michael Macaulay
}

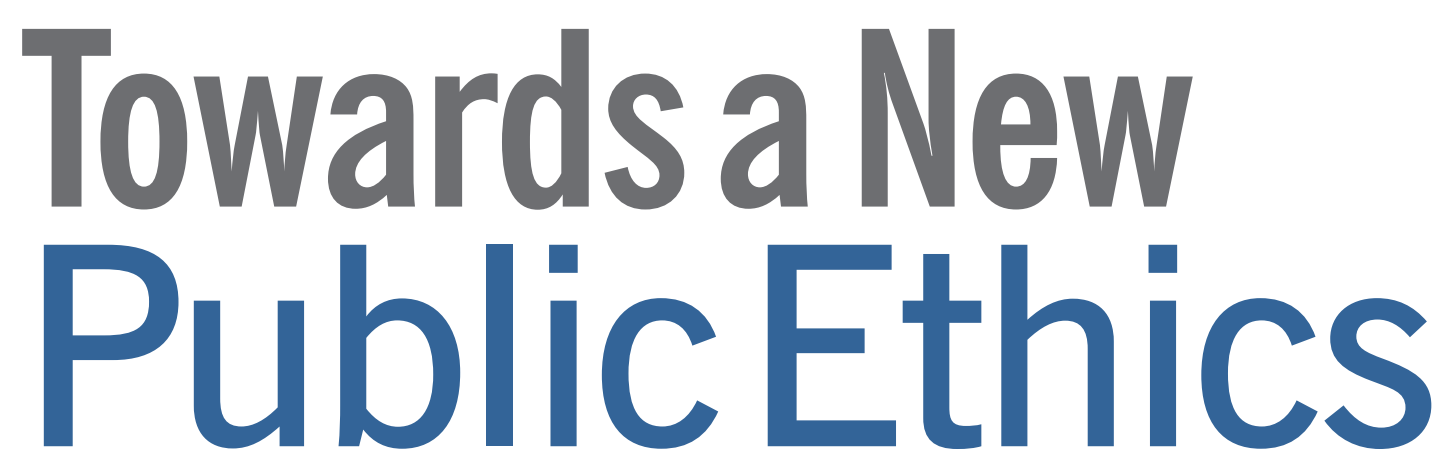

\begin{abstract}
This article is a very slightly modified version of Michael Macaulay's Victoria University of Wellington inaugural professorial lecture, of the same title, which was delivered on 5 November 2019. It offers an overview of misconduct issues in the New Zealand public sector, and an explanation over the causes of toxic workplace cultures. It ends with a plea to develop a more specifically care ethics approach, to augment current public ethics perspectives. The lecture draws on seven years of accumulated research but foregrounds results from the three-year, ARC-funded Whistling While They Work 2 research project, for which Michael was the New Zealand lead.
\end{abstract}

Keywords New Zealand, ethics, misconduct, organisational culture, care

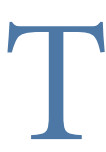

The last time I gave an inaugural lecture was in 2011, when I was Professor of Public Management at Teesside University in the UK. At that time I had recently been involved in a minor spat with then-Prime Minister David Cameron over a major piece of research my team and I had published on corruption in the UK for Transparency International (Macaulay, 2011). Cameron flatly denied that there was any corruption

Michael Macaulay is Professor of Public Administration at the Wellington School of Business and Government. in the UK and disagreed with many of our findings. At the time I was taken aback by these claims, not least because about two weeks after sending us his critique came the first of his government's ministerial resignations precisely on the grounds of corruption. I think history has shown that it wasn't the last time that Cameron miscalculated a response to perceived criticism.
I am now privileged to live in beautiful Aotearoa, where we are consistently ranked among the top two or three least corrupt countries in the world, and whose prime minister is globally recognised as possibly the best example of an ethical, responsible leader currently working in modern politics. Only last week former FBI director James Comey revealed himself as yet another prominent US citizen who wants to move to New Zealand. No wonder that many colleagues in the UK assumed I was moving to New Zealand for some form of pseudo early retirement, as there is so little to research.

But of course that's not really the case. Only within the last few weeks a new inquiry has been launched into bullying in the New Zealand Police, which follows fairly hot on the heels of a damning report into the same behavioural issues in Parliament. The prime minister's party is still embroiled in a sexual harassment scandal which, in classic tradition, has become much worse due to the perception of cover-ups surrounding it. My own research, which obviously I will be touching upon this evening, reveals what the key issues facing the New Zealand public service are. 
This lecture will explore such themes in three ways. First, it will offer a diagnosis of the ethics issues facing the public service (and, more broadly, public life). Second, it will outline an explanation for many of these issues, although time probably won't enable me to look at all of them. Third, it will argue for some ways forward for us to reconsider these issues; not necessarily to solve them, but to begin to resolve them.

The idea that such solutions can come from one person, or a small group of people, is in itself part of the problem. Ethics problems are socially experienced and understood; they can only be properly resolved through social interaction and meaningful conversations. They are not owned by academics; nor are they owned by public servants alone. Hence the title of this lecture: there can be no new public ethics without a public.

Before getting to the heart of the discussion it may be useful to add a couple of caveats. The first is that the observations tonight are the product of research and evidence and are not simply critique. ${ }^{1}$ To reiterate, New Zealand's reputation for having a high-trust, high-integrity public service is entirely deserved. It is a shame, in a sense, to have to add this caveat but it is important to emphasise. Many times in my near-seven years in New Zealand I have observed research being diminished and rejected as being negative, when it is only trying to illuminate genuine problems.

So please do not misunderstand my intent this evening. I will not be critiquing any agency, nor the public service generally. And I must stress that every single issue that is being discussed tonight applies equally if not more so to the world of academia. I am not speaking from a position of moral superiority. In fact, I am willing to wager that what I discuss is neither more nor less than the experiences that a majority of people in this very room have experienced. In fact, I am going to go further. For much of this discussion the voice you will hear is not mine - it is yours, the voice of the New Zealand public service, being reflected back onto itself.

\section{Diagnosis}

What, then, are the main integrity issues facing New Zealand? They are not issues of hard corruption or bribery, which do

exist but in relatively isolated incidents. They are issues of behaviour. Our research on misconduct and internal reporting shows these problems very clearly. Our work shows conclusively that bullying is the single most observed and reported form of misconduct in the New Zealand public service. This is probably the least surprising observation of the lecture.

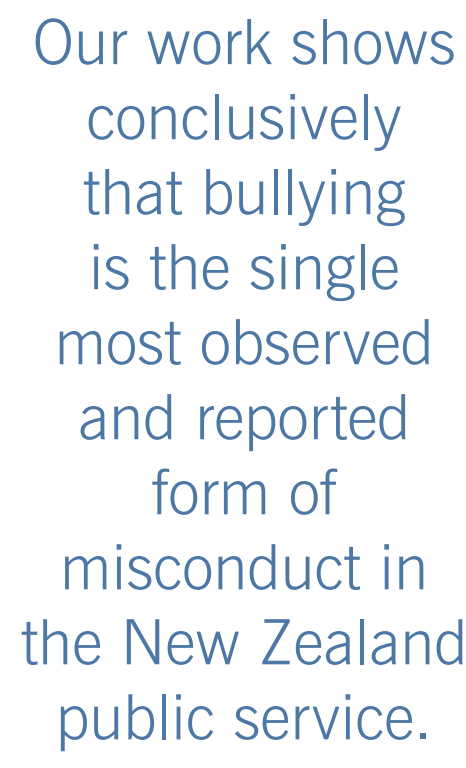

In just the past few days an inquiry has been launched into bullying in the New Zealand Police, headed by Debbie Francis. Francis, let's not forget, only published her report into bullying in the New Zealand Parliament in May. Over the years my friend and colleague Geoff Plimmer has produced significant evidence of the prevalence and harmful effects of bullying. The Public Service Association has produced much research which has reinforced this view. In 2013 the State Services Commission's own Integrity and Conduct survey found the same. And, of course, it is not just the public sector. In June this year we learned that New Zealand has the second highest rate of school bullying among all OECD countries.

What has brought this home to me on a much more personal level, however, are the public servants I teach. Over the last seven years I have run a course on public integrity for students doing Victoria's Master of Public Policy and Master of Public Management degrees. The students are overwhelmingly New Zealand public servants who are still working in important leadership roles. Every year we begin with a self-reflective essay on an ethics issue they either face or have recently had to contend with. Nearly every essay has been about bullying in varying forms: psychological, always emotional, occasionally even physical. My students have been crying out for years on this issue.

\section{Explanation}

Why does it happen? The answer is simple to understand and, of course, deceptively difficult to counter. It is a combination of individual, cultural and systemic issues.

The vast majority of work in this field - both academic and in various inquiries, consultancies, etc. - focuses on the first two elements. It is often unhelpful to make predictions, but I am sure that the new inquiry into the New Zealand Police will do so too. This is because so much work has already been done on police cultures around the world, and in New Zealand in particular as has already been shown to be the case, over and over again. Very little is unknown about this area.

Toxic workplace cultures allow poor behaviour to thrive. As we can see from our recent research in New Zealand and Australia, but also from decades of research preceding it, these always have a combination of the same specific factors.

Ineffective leadership. For the purposes of this lecture, the following may seem slightly unscientific so please don't raise your hands, but how many people here have experienced serious issues at work that have simply been either managed away, or where the person who has created chaos has even rewarded? It could be a passive reward (for example, other people picking up the mess that they have caused), or it can be an active reward: there are no small number of cases of people being promoted out of a problem. Again, I'm very willing to wager that many of you have witnessed this at first hand. This is done because leaders can't or won't make decisions that will confront an issue. I would hesitate to suggest that this behaviour is due to a lack of moral courage, and very often the decision makers are themselves in a bind. But such 
behaviour isn't helpful. Our research also shows that leadership issues can be exacerbated as leaders tend to overestimate their own ethical judgement and abilities, compared to the perceptions of their followers.

- Poor processes. There is a lack of process, or at least an unclear process that makes accountability very difficult to follow. New Zealand did not rate as highly in terms of robust processes as Australian jurisdictions (Brown and Lawrence, 2017)

- External reputation above everything. Organisations will go through all sorts of moral wriggling to ensure that their reputations are protected in the outside world.

- Internal silence. Closely linked with the above, when a person finds out something has happened without them knowing it makes them feel isolated and disempowered. Again, I ask members of the audience to think of your own experiences to see how much this may resonate. In more extreme cases it can lead to perceived cover-ups, non-disclosure agreements and 'quiet words' with people. There may be good reasons for any of this behaviour, but if there is silence around it, the person most affected does not know. And we all know that huge stress is created from not knowing. As a result, even if leaders think this is the best course of action, the outcome is usually the opposite: people who come forward do not feel protected or supported. Silence overwhelmingly protects the organisation.

- Trust. It is absolutely true, and it is completely justified in my view, that levels of public trust in New Zealand are very high, particularly for the public service in general, but also in specific institutions such as the Police. People work very hard to build and maintain that trust relationship and it should be both celebrated and cherished. Conversely, however, trust within an organisation can become neglected. I was honoured a couple of months ago to offer a summary of the third IPANZ public sector conference. I don't know how conscious it was, but trust was the issue that came up again and again with nearly every speaker and the message was largely the same. Agencies of all sizes and shapes are working tirelessly to promote public trust. Too many agencies are overlooking the trust of the teams within. That is where the fault line is, my friends, and it needs to be healed by not losing the public focus (never do that), but not allowing that to morph into protectionism.

\section{Some generalisations can be so bad that they work on the basis of the Forer effect - the psychological bias that enables people to read into statements whatever
they wish.}

- Myth of exclusivity. Finally, I would argue that the other common denominator in toxic cultures is an obsession with exclusivity. Every agency believes it is unique. Agencies within agencies believe that they are unique. Look at the building we are in. To a non-academic there might be a belief that academic culture is unique. To academics outside the university there may be a perception that Victoria has its own unique culture. Each faculty may believe it has a unique culture. And, within those faculties, each school usually considers itself to have its own culture. And, in fact, within each school there can be subcultures. So, within a single institution - this very university - we cannot talk about a 'culture' but really a cultural pyramid scheme, each part fuelled by a conviction that it is unique. It is all nonsense. They are all very different, for sure, but difference isn't uniqueness and there are far more unifying factors than differentials.

Exclusivity is the one area that I respectfully disagree on within the magisterial report on parliamentary bullying (Francis, 2019). The report concluded that the institutional context within Parliament was so different that its very uniqueness promoted its poor behaviours. I cannot agree because the report found the same combination of factors outlined above (plus a few more I don't have time to mention). Far from being unique, the bullying in Parliament is the same old combination of toxicity.

Again without wishing to be too speculative, I am sure the New Zealand Police report will find these same factors too. It will also find that there is no single police culture but a network of subcultures that cross location, rank and levels of behaviour, just as in all other police forces across the globe.

What is pernicious about the misguided belief in exclusivity are the cumulative effects of its logic. If we are unique then nobody can understand us. If nobody can understand us, then they have to become one of us to do so. In order to become one of us, they must follow our codes, rules and 'the way we do things around here'. In order to do that you must effectively become initiated. Those who won't or don't become initiated are ostracised, explicitly or tacitly. Outsiders are neither trusted nor welcome. And on it goes.

We have seen these patterns time and time and time again, throughout history and across both sectors and jurisdictions. People have been writing about this for years. It doesn't change. You know what I'm talking about because it has happened to you. It might be happening to you right now. It is crucial to reiterate: difference is not exclusiveness. More things unite us than separate us.

\section{Systemic solutions}

The individual and cultural aspects of organisational and/or public ethics are thus very well understood and are an extremely lucrative business opportunity for consultants and, to a slightly lesser financial extent, academics. Solutions are 
very often couched in generalisations that border on platitudes. One recent report for the Australian public service concluded that ethical leadership is important and is needed. Can there be a more obvious truism? Respectfully, that is not a very valuable conclusion.

Some generalisations can be so bad that they work on the basis of the Forer effect - the psychological bias that enables people to read into statements whatever they wish. A very general statement can have almost mystical significance, simply because people have attributed their own meaning to it. Go into any airport bookshop and you can find reams of such work.

Deeper and more nuanced solutions are far less popular and they are more difficult to sell, and that is because they are far more difficult to implement. I'm very proud to be part of the Whistling While They Work 2 project because it has offered practical guidance throughout: towards legislation; organisational improvements (Brown et al., 2019). It does not rely on generalities or promote something that would be nice to achieve. We say what works and tell you how to do it. But even that only attends to one set of organisational cultural aspects.

That is because we need to collectively work on much deeper, more systemic solutions. These are by their nature extremely complex and so ingrained that it is impossible to approach, or even discuss, them as individuals or small groups. In this age of climate justice, though, I believe that we are moving towards a much broader and more caring social consciousness, which will continue to be fuelled by environmental necessity, so I am very optimistic. My two boys are here tonight. I hope they will be part of positive change.

When I use the word systemic I mean deeper political, economic, social and value-based ideas. And obviously we could discuss so many of these, but not only does time not permit me to do so; it inevitably will lead us into too expansive a terrain. Bringing it back directly to public service ethics, the systemic issue I'd like to highlight is one that definitely affects New Zealand, but is also equally not a 'New Zealand problem'. It is an issue that affects all jurisdictions, though perhaps more so developed democracies, because it is the

problem of the ethical orientation of how we visualise the public service.

As a broad rule I'm sure we are all aware of the five major ethical orientations. In class I usually call them our five ethical senses, as they correspond to the way we perceive ethical issues. As in biology there

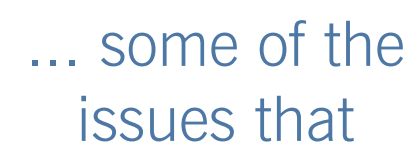

we may see in

New Zealand are not 'New Zealand issues' at all, but a lasting legacy of systemic thinking about bureaucracies, democracies and what the public service is.

are, of course, more than five senses, but these will do for now:

consequentialism - looking at the outcomes of our actions, which includes various forms of utilitarianism (greatest good for greatest number, etc.);

deontology - what are we obliged to do and to whom, which includes the promises we make, either explicit or tacit;

virtue - what are the characteristics that make us 'good' people and enable us to attain the good life, for ourselves and for others?;

justice - what makes a decision fair, and for whom?;

care - which is not only about considering the human side of an ethics issue, but a different orientation altogether: whereas the previous four are universalist in outlook, looking to create abstract principles that we can apply across situations, care ethics looks at specific, concrete situations that rely solely on context.

In any given situation we usually - even subconsciously - apply a number of these perspectives. It is interesting, too, to see how they are applied in commentaries on others. For a few years virtue theory was quite unfashionable, but with the rise of Trump, Johnson and other recent political leaders it is almost exclusively used as a means of denigration. Praise for our own prime minister also frequently focuses on the perceived quality of her character.

I would argue, however, that decades of thought on public administration - which includes here public policy, public management, and the relations between politicians and public servants - has been geared towards universalist principles. How can it not be? It is not easy to create public policy on an individual basis. I would further argue that in terms of such principles, the principle orientation has been around two of these perspectives: obligations and justice.

All of the cultural factors that I mentioned earlier in this lecture pivot around these two principles. When we look specifically at bullying we see this time and again. The principle organisational reaction is to protect the organisation and ensure fair process. These are understandable aims and I'm not arguing against fair process. But, as in real life, level playing fields are actually tipped heavily in favour of those at the stronger end of power differentials.

The most horrendous downside to these perspectives is a descent into what Guy Adams and Danny Balfour (1998) have identified as 'administrative evil'. The concept of administrative evil develops Hannah Arendt's seminal observations about the dehumanising power of bureaucracy and its tendency to enable people to do terrible acts. The Milgram experiments put that theory into action: a faceless authority figure is all it takes for people to do terrible things. Arendt was talking principally about the Holocaust, but there is no shortage of recent examples: Trump's concentration camps along the southern US border; the UK's treatment of the Windrush generation. The people who 


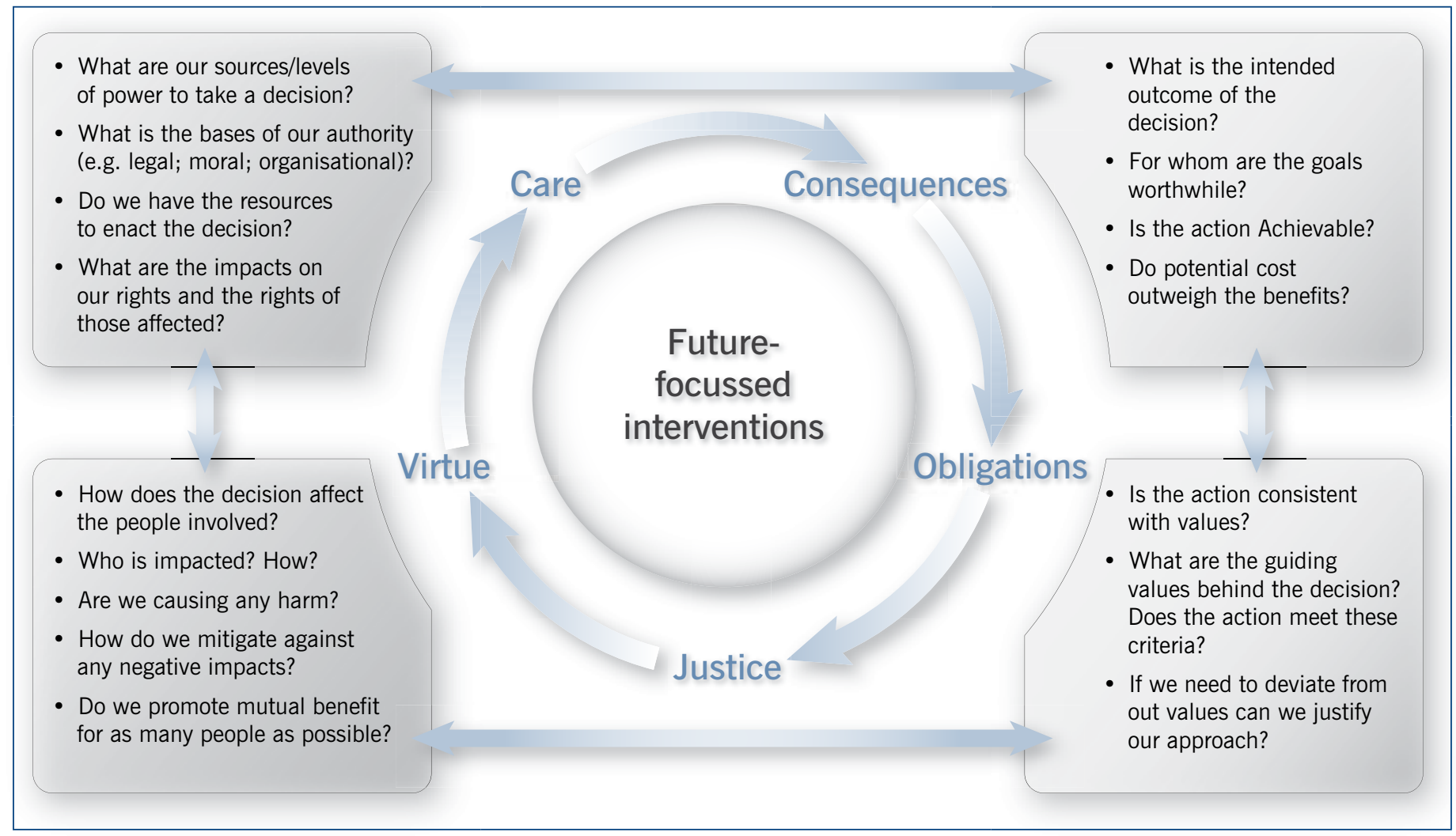

implement these things are almost certainly lovely in most respects, yet through the mask of loyalty to the organisation and the sense that it's fair because it's an order to be followed they can engage in acts that shock and repel other people.

Is there a New Zealand equivalent? Yes; lots. You know them and unless we humanise public administration we will continue to face these issues.

Systemic issues can and do improve, however. This future generation is showing that a change in social values leads to so many changes to the world. What I suggest we need to think about at this level - and again I say think about because I believe this needs to be a collective set of decisions - is the basic orientation of public service ethics. Here is one such framework that students and I put together collectively in one of my master's courses, which we denoted ethical stewardship (Figure 1).

The framework can be used as a heuristic device: as rules of thumb that are easily recalled, rather than as anything deeply philosophical. The model is in a well-mined tradition of ethical decisionmaking frameworks, but this one specifically entails different ethical senses and also looks to a longer-term perspective. It is as strategic as it is reactive.

\section{Conclusion}

Obviously this is just one set of issues, but it is one that, I hope, you will agree is central to the idea of public service ethics. It also shows that some of the issues that we may see in New Zealand are not 'New Zealand issues' at all, but a lasting legacy of systemic thinking about bureaucracies, democracies and what the public service is.

And on that note I leave with a note of optimism and a challenge. The optimism is simply that the power to make changes is ours to use, but in order to do so we need to work together. I genuinely believe that the New Zealand public service may have issues, but that these are very similar to those in just about every other walk of life. And I also believe that the people who make up the public service are noble and aspirational people who are committed to improving well-being. My only concern is that they are hidebound by thinking that is 700 years old.

Which brings me to my challenge, which is primarily directed towards my fellow academics. It cannot have escaped some people's attention that I have cheekily titled this lecture 'Towards a New Public Ethics.' My colleagues will recognise this as a branding issue: ever since New Public Management became a thing there has been a rush to slap the words 'new public' on just about everything.

For those who did notice, then you are absolutely correct - I did that deliberately as a nod to that tradition. I also did it, however, because I really do think we need new approaches at systemic levels, particularly to expand our orientation away from obligation and justice, and towards a greater orientation of care. And I also did it because - ironically - there is nothing at all new in this idea.

The final challenge is to what seems to me to be the unending desire to keep rebranding very well-known ideas as 'new'. New Public Management wasn't particularly new, and I would argue wasn't even an actual thing. The history of thought in public policy, management and administration is one of evolution and emergence. That we craft labels for different phases of this thought is fine, but it's not real.

I respectfully suggest that it is symptomatic of what I call imperial thinking' - the idea that because something is new to us then it must be new to all, in the same way that discovering a piece of land that has been inhabited for hundreds or even thousands of years suddenly makes that a new country. We can take all of the 
modern frameworks and thinking we have and see how they have been used for centuries. If anybody really wants to understand why Trump's chaotic leadership is sadly effective in its own way, just read chapter 17 of The Prince by Machiavelli; although I'm sure he hasn't. If anybody wants to understand concepts such as servant leadership, upon which entire reputations and careers have been built in the last few decades, I suggest talking to any of our Samoan sisters and brothers about tautua, which has been around for ever. The list goes on.
As for my role, I continue to be honoured to try and help create and disseminate knowledge in this area, which I can do only through my own learning. My future research plans include collaborating with some of my colleagues in this room to continue work on improving processes around internal reporting, and identifying the strategic value that anti-corruption and pro-integrity work can bring. But all of it will be done collectively.

Instead of trying to colonise knowledge as a branding opportunity to sell ourselves as great thinkers, we perhaps ourselves need to exercise a care perspective towards those with whom we are trying to share our ideas. And we do so by listening to the public, in all its myriad and glorious manifestations. There can be no new public ethics without the public.

\footnotetext{
It should be noted that although this lecture draws on an accumulated seven years' worth of work, much of it is being taken from the Whistling While They Work 2 suite of research. This is the largest project of its kind ever undertaken, and looks at internal reporting and misconduct in public, private and not-for-profit sectors across Australia and New Zealand. I would like to acknowledge the support of the State Services Commission and the New Zealand ombudsman for the New Zealand work, and the leadership of Professor A.J. Brown at Griffith University who devised and led the project.
}

\section{References}

Adams, G.B. and D.L. Balfour (1998) Unmasking Administrative Evil, New York: Sage

Brown, A.J. and S. L. Lawrence (2017) Strength of Organisational Whistleblowing Processes: analysis from Australia and New Zealand, Brisbane: Griffith University

Brown, A.J., S. Lawrence, J. Olsen, L. Rosemann, K. Hall, E. Tsahuridu, C. Wheeler, M. Macaulay, R. Smith and P. Brough (2019) Clean as a
Whistle: a five step guide to better whistleblowing policy and practice in business and government, Brisbane: Griffith University

Francis, D. (2019) Bullying and Harassment in the New Zealand

Parliamentary Workplace, Wellington: New Zealand Parliament

Macaulay, M. (2011) Corruption in the UK, vols 1-3, London:

Transparency International UK

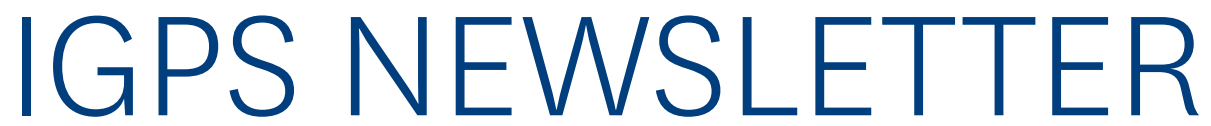

"Across the world, biodiversity is plummeting. The numbers are unprecedented and they are terrifying: estimates are that we are now losing species at 1,000 to 10,000 times the background or natural rate. Nowhere is the loss of biodiversity more pronounced than here in New Zealand."

Mike Joy, IGPS newsletter editorial, April 2019

\section{"The current tax and transfer system does not achieve} the fairness and justice the Tax Working Group was asked to consider. Nor does it promote economic efficiency or environmental sustainability.”

Michael Fletcher, IGPS newsletter editorial, August 2019

"Given its constitutional importance, this bill reforming the public sector is not the product of a sufficiently high quality, considered and rigorous process. The failure of process is evident in the quality of the bill, which falls short of the highest standards."

Simon Chapple, IGPS newsletter editorial, January 2020
— very fortnight the IGPS sends out a free newsletter, accessible expert analysis of topical issues. The newsletter highlights our upcoming events, as well as those run by Victoria University's School of Government and others our subscribers might find interesting.

Recent events have featured Sir David Skegg, epidemiologist, public health physician, and former ViceChancellor of the University of Otago, Sophie Handford, organiser of New Zealand's involvement in the School Strike 4 Climate movement, His Excellency Seung-bae Yeo, ambassador to New Zealand from the Republic of Korea, and Peter Fraser, economist and a leading authority on the dairy industry.

To subscribe to the newsletter, send an email to igps@vuw.ac.nz with subject line "subscribe to newsletter".
Institute for Governance and Policy Studies

A research institute of the School of Government 